\title{
Hermenêutica Medieval: a Compreensão ESPIRITUAL DE JOAQUIM DE FIORE
}

\author{
Noeli Dutra Rossatto ${ }^{1}$
}

\begin{abstract}
RESUMO: $\mathrm{O}$ estudo trata a hermenêutica medieval sob o prisma da compreensão espiritual (intelectio spiritualis) de Joaquim de Fiore (1135-1202). Mostra que a noçấo de Trindade serve de base para retomar o método alegórico e o tipológico da tradição. Além disso, serve para propor o novo método por concórdia que, a nosso ver, culminará na maior inovação da leitura da história medieval. Entre os resultados, destacamos a continuidade imediata dessa hermenêutica com os franciscanos espirituais do século XIII e sua influência direta na cultura luso-brasileira. Avaliamos também os estudos que tentam encontrar em Joaquim a gênese da filosofia da história hegeliana. Por fim, analisamos sumariamente a proposta de Gianni Vattimo, que encontra o novo sentido do cristianismo no legado joaquimita.
\end{abstract}

PALAVRAS-CHAVE: Hermenêutica. Joaquim de Fiore. Exegese. Alegoria. Tipologia.

Poucos são os estudos de hermenêutica medieval que incluem a obra de Joaquim de Fiore (1135-1202). Talvez isso se deva em parte a que, desde muito cedo, ela foi condenada como herética, ou porque a ela estiveram associados os mais diversos movimentos heterodoxos, proféticos e apocalípticos. Tal ausência, no entanto, contrasta com a subterrânea recepção de seu legado pela posterioridade filosófica. Também contrasta com os resquícios que ela deixou em algumas manifestaçôes populares ligadas à cultura luso-brasileira e em alguns episódios recentes da nossa história. E mais, contrasta com aqueles

\footnotetext{
${ }^{1}$ Doutor em História da Filosofia (Medieval) pela Universidade de Barcelona. Professor Associado do Departamento de Filosofia da Universidade Federal de Santa Maria (UFSM), RS. Atua no Programa de Pós-Graduação em Filosofia nos temas de hermenêutica e ética. Livros publicados: La hermenéutica medieval (2011); Diferença, cultura e educação (2010); Filosofia e Educação - confluências (2005); Joaquim de Fiore: Trindade e nova era (2004); O simbolismo das Festas do Divino (2003); Ética e Justiça (2003). Publicou vários capítulos de livros, artigos em revistas nacionais e internacionais e traduçōes do latim e francês. Email: <rossatto.dutra@gmail.com>.
} 
traços do joaquimismo encontrados nas modernas filosofias da história ou em algumas reapropriaçôes contemporâneas.

Em vista disso, cabe perguntar primeiramente: em que a hermenêutica joaquimita se diferencia da herança da tradição patrística e medieval? E inda, em que reside o espírito inovador, heterodoxo ou mesmo revolucionário desse novo modo de interpretar? E, por fim, qual a atualidade de sua proposta?

O presente estudo parte da suposição de que Joaquim de Fiore dá um novo estatuto teórico à exegese da tradição patrística e medieval. E é com base nesse estatuto que ele procura não só revigorar e dar sentido aos antigos métodos de interpretação, sobretudo o alegórico e o tipológico, mas também, ao lado disso, propõe um novo modo de compreensão: a compreensão espiritual por concórdia. Os principais estudiosos do tema, entre os quais podemos elencar Ernesto Buonaiuti (1931), Herbert Grundmann (1966), Henri De Lubac (1961) e Henry Mottu (1977), coincidem ao dizer que a exegese da tradição, tal como havia sido concebida pelo pensamento patrístico, e da forma como estava sendo praticada ao longo da Alta Idade Média, sofrerá uma profunda mudança nas mãos de Joaquim.

Não obstante, ainda que essa mudança seja facilmente constatada por diversos estudiosos do tema, não é tão fácil identificar o real corte produzido pela contribuição da hermenêutica joaquimita no vasto tecido da tradição. Difícil é diagnosticar, por exemplo, o que efetivamente foi alterado ou se manteve dos métodos alegórico e tipológico. De igual modo, não é fácil indicar com precisão as implicaçóes que, para a leitura da história, resultaram da aplicação do singular método por concórdia proposto pelo abade. A propósito desses aspectos, a historiografia crítica não encontra consenso. Alguns, por exemplo, vão entender que Joaquim utiliza o método alegórico da mesma maneira que a tradição alexandrina. Outros vão aproximar em demasia o método tipológico e o por concórdia, entendendo a ambos sob o rótulo da tipologia histórica da Escola de Antioquia. Outros mais vão encontrar na proposta joaquimita apenas a idiossincrasia depositada no exagerado acento dado à tripartição dos procedimentos metodológicos (alegórico, tipológico e por concórdia) ou aos estados de história (Pai, Filho e Espírito), sem considerar a substancial unidade que articula os mesmos.

Em termos conjunturais, Joaquim se move pela certeza de que estava vivendo o final de um período: o segundo estado do mundo, atribuído ao Filho e protagonizado pela figura de Jesus. Tal certeza lhe causava uma 
profunda angústia que se somava à impotência de não poder interpretar os textos bíblicos, especialmente os apocalípticos, e os eventos daquele conturbado século XII, com o auxílio das técnicas exegéticas da tradição. Daí não lhe restava alternativa: era preciso elaborar um "novo modo de exposição" (novum genus exponendum) dos mistérios bíblicos, a fim de tornar possível a compreensão da escritura e sua consequente aplicação à leitura da história em curso. É o que assinala com todas as letras o Prefácio da Concordia Novi ac Veteris Testamenti (JOAQUIM DE FIORE, 1964a, f. 2c), livro em que o abade expóe sua proposta metodológica: "[...] as longas e multiplicadas admoestações dos Padres (da Igreja) já perderam seu sentido, devido às fastidiosas repetições”. Por isso, era preciso rearticular um novo modo de interpretar as escrituras, que fosse apropriado para compreender os sinais dos tempos.

O contexto imediato em que se insere a obra joaquimita, como toda literatura de corte apocalíptico, é um mundo em crise. E isso era agravado à medida que, além da ineficiência dos métodos de leitura da história (lectio historiae), e da crise do modelo monástico, por aqueles dias, o grande líder muçulmano Saladino acabava de retomar Jerusalém, o que colocava em marcha os exércitos cristãos da terceira cruzada (1189-92).

Nesse contexto, Joaquim vai propor uma reformulação da hermenêutica bíblica com base em um novo paradigma: a noção de Trindade. Trabalharemos com a hipótese de que essa noção protocolar, como princípio regulador de todo sistema, possibilitará ao abade distinguir e dar novas funçóes aos diferentes métodos da exegese da tradição, sobretudo o alegórico e o tipológico, bem como propor o novo método por concórdia.

\section{Alegoria e tipologia}

Em chave trinitária, Joaquim retomará os antigos métodos de leitura da história, submetendo-os a novos critérios e dando um lugar preciso em seu sistema hermenêutico. E, em um passo adiante, proporá um terceiro método que, a nosso juízo, provoca a mais radical inovação na racionalidade histórica posterior a Agostinho e à crise posterior ao primeiro milênio cristão. Tratase do método por concórdia. Podemos desde logo afiançar que seu sistema hermenêutico está composto por três métodos que visam à compreensão espiritual: o alegórico, o tipológico e o por concórdia. 
Uma das diferenças fundamentais entre a obra hermenêutica de Agostinho e a de Joaquim é que a primeira firma como paradigma o disperso e nem sempre consensual conteúdo da doutrina cristã (doctrina christiana); a segunda, por sua vez, encontra amparo e coerência na imagem (imago) da Trindade, entendida como Primeiro Princípio. No Psalterium decem chordarum, Joaquim (1964b) define o Primeiro Princípio uni-trinitário nos seguintes termos: tres sunt unum et unum tres, isto é, três são um e um (são) três.

Cabe aqui uma questão: por que, segundo Joaquim, a alegoria e a tipologia da tradição não dão mais conta da leitura da escritura e da história em curso?

Para responder adequadamente a essa questão, é preciso, de saída, observar que a compreensão alegórica e a tipológica não indicam metodologias equivalentes em seu sistema hermenêutico. Hoje, alguns estudiosos do tema, como é o caso de Frances Young (1977), têm insistido na tese de que, ao longo da tradição patrística e medieval, essas duas práticas exegéticas implicaram um mesmo procedimento compreendido sob o nome de hermenêutica figurativa. Tal argumentação se apoia numa alegação etimológica atinente à sinonímia dos termos "figura" e "tipo", ao longo da cultura cristã. Além disso, eles agregam que, rigorosamente, o emprego técnico do termo "tipologia” é moderno, resultando em anacronismo encontrá-lo em um procedimento medieval.

Da perspectiva de Joaquim de Fiore, esses dois argumentos são inconsistentes por duas razóes principais. Primeiro, porque o abade não só usa tecnicamente o termo "tipologia" em seus textos como também estabelece uma distinção precisa entre a compreensão tipológica (intelligentia typica) e a alegórica. Segundo, porque esses dois procedimentos não só se distinguem como também rivalizam ao longo do pensamento patrístico e medieval anterior a Joaquim, como já demonstramos (cf. ROSSATTO, 2011).

Assinalamos anteriormente que o sistema hermenêutico joaquimita se ampara na noção de Trindade. De acordo com o Primeiro Princípio unitrinitário, Joaquim estrutura seu sistema hermenêutico e sua teoria da história. Em similitude com a Trindade, ele habilita três modos de compreensão, que funcionam como se fossem um só: a compreensão alegórica, a tipológica e a por concórdia. Da mesma forma, a teoria da história se ampara em uma estrutura ramificada em três estados (status) que, entrelaçados, compóem uma totalidade que abriga em seu interior as diferentes subdivisóes formadas pelos vinte e um conjuntos compostos por quarenta e duas geraçóes (generationes), 
distribuídos sincronicamente no decorrer de sete idades (aetates) e de cinco tempos (tempora).

Em sentido amplo, os dois primeiros modos de compreensão, o alegórico e o tipológico, seguem as regras da proporção por dignidade, e servem para apreender a multiplicidade disposta na dimensão espaço-temporal da história. A multiplicidade dos sentidos (sensus) da escritura será obtida mediante a admissão de variantes internas a esses dois modos de compreensão. A categoria de relação (relatio), em sintonia com a teoria das cinco relaçóes interpessoais da Trindade (quatro ab intra: A-B; B-A; AB-C; BC-A; e uma ad extra: $\mathrm{ABC}-\mathrm{D}$, onde: $\mathrm{A}=\mathrm{Pai}, \mathrm{B}=$ Filho e $\mathrm{C}=$ Espírito), será utilizada como balizadora dos cinco sentidos da compreensão alegórica. Temos, assim, cinco sentidos alegóricos: o histórico, o moral, o tropológico, o contemplativo e o anagógico. Os sete modos próprios de dizer a Trindade de Deus qua Deus (A, $\mathrm{B}, \mathrm{C}, \mathrm{AB}, \mathrm{AC}, \mathrm{BC}, \mathrm{ABC}$ ) darão o padrão das sete variantes tipológicas.

Ao recompor esses dois modos de apreensão da multiplicidade do sentido da escritura e da história (que para o abade náo mais se distinguem), Joaquim se afasta das antigas estratégias de interpretação da hermenêutica precedente. Um dos distanciamentos se dá em relação à alegoria, que não mais será pensada com base na simples oposição entre letra e espírito, como no platonismo radical da Escola de Alexandria. Também há o estabelecimento de critérios para reduzir a multiplicidade do sentido. Os sentidos alegóricos agora são cinco, e não mais que isso. E estão justificados com base nas cinco relaçóes interpessoais da Trindade. Com isso, o abade calabrês procura sanar uma das anomalias carregada pela alegoria praticada até o século XII, que resultava na desvairada proliferação de sentidos. A crítica dirigida ao método alegórico era a de que ele já não mais sabia o que e como interpretar; e, por isso, acabava interpretando tudo de forma alegórica. É certamente dessa distorção que nasce o preconceito - até hoje repetido por alguns - de que a interpretação simbólica da Idade Média utilizava um ilimitado poder expressivo, que não conseguia abarcar mais nada em concreto.

Não sem razão os estudiosos do século XII vão sugerir que o simbolismo do período era tão difuso que resultava em uma verdadeira orgia simbólica (cf. CANTIN, 1996; VERGER, 1997); e hoje, na esteira disso, alguns retomam esse lugar comum, comparando-o à explosão da imagem no mundo contemporâneo (cf. MAFFESOLI, 1995, p. 102-3). Dentro desse quadro, a nosso ver, insere-se igualmente a reação nascida no seio da escolástica do século XIII, especialmente a de Tomás de Aquino, pautada na substituição 
de toda e qualquer forma de linguagem figurada pelo sentido literal, e na utilização do instrumental teórico baseado nas três disciplinas do trivium (a lógica, a gramática e a retórica).

O distanciamento provocado pela tipologia joaquimita no que concerne à da tradição é bem mais problemático, se levarmos em conta a repercussão de sua proposta. A antiga tipologia não dava conta da interpretação dos tipos históricos que ocorreram depois do tipo "Cristo", pois ele adquirira um significado meta-histórico para o qual todos os tipos anteriores deveriam necessariamente convergir. O resultado era um déficit de racionalidade histórica na exegese do período correspondente ao segundo estado do mundo, atribuído ao Filho; e de todo o terceiro estado, atribuído ao Espírito. Tal instrumental se mostrava mais impotente ainda nos séculos imediatamente posteriores à passagem do primeiro milênio da encarnação do Filho. Até esse momento, a proposta agostiniana, em uma versão milenarista, parecia resolver o problema. O agostinismo milenarista dividia a história em sete idades, Cristo estava situado no momento da passagem da quinta para a sexta, e a sétima seria vivida fora deste mundo. Supondo que a cada idade corresponda mil anos, o ano mil da encarnaçáo de Cristo marcaria o término da sexta idade; e, com efeito, o fim da aventura humana na terra. Não obstante, depois da ressaca do primeiro milênio cristáo, e na perspectiva de um novo alvorecer do medievo, o método tipológico se mostra cada vez menos competente para levar a cabo uma efetiva tarefa de interpretação da história à luz das escrituras. Em suma, a tipologia até então vigente não conseguia mais significar e dar sentido aos tipos e eventos relativos ao período posterior a Cristo. Aliás, a tipológica tradicional só conseguia dizer que todos os tipos precedentes ganhavam significado e sentido na relaçáo com este tipo máximo, e os tipos futuros não eram importantes.

De outra forma, a tipologia joaquimita, resgatada da Escola de Antioquia, sem abdicar da contribuiçấo legada pela Escola Monástica medieval, continuará a dar significado às figuras e aos eventos históricos de acordo com a lógica do anúncio e da realização; porém, diferentemente da tradição, hierarquizará os personagens no decorrer de três estados (status) do mundo. Por exemplo: Adão, personagem do estado paterno, que até então encontrava seu correspondente mais elevado no tipo Cristo, agora ganhará um significado mais elevado ainda em um novo e futuro personagem (uma espécie de Christus redivivus) a acontecer no terceiro estado do mundo. E assim sucedia com todos os tipos significativos do estado filial. 
Ao refazer a alegoria e a tipologia, Joaquim acredita que não só estava habilitado para interpretar o Antigo Testamento como anúncio do Novo, mas também o Novo como anúncio de um terceiro testamento espiritual: o por ele chamado de Evangelho do Espírito ou Evangelho Eterno. Já tratamos dessa temática em outro momento, por isso, não voltaremos a ela aqui (cf. ROSSATTO et al., 2010).

Cabem, então, algumas questôes: em que a concórdia se distingue da alegoria e da tipologia? Por que propor um terceiro modo de compreensão espiritual da escritura e da história? Que função esse novo método desempenha no sistema hermenêutico joaquimita?

\section{A COMPREENSÁO POR CONCÓRDIA}

Para responder à primeira questão, temos de começar por admitir que a concórdia, como terceira estratégia do sistema hermenêutico, traz, por sua vez, a marca propriamente joaquimita. Se, na significação e na distribuiçáa dos personagens, a alegoria e a tipologia estão pensadas a partir da proporção por dignidade, a compreensão por concórdia seguirá os critérios provenientes da proporçáo por igualdade numérica. Se as duas primeiras estratégias se abrem, ainda que de forma controlada, para a apreensão da multiplicidade do sentido, a terceira remeterá indiscutivelmente a uma plena unidade de sentido. Em acréscimo, se as duas primeiras estratégias emulam as relaçóes intra e extratrinitárias das pessoas divinas, a terceira se pautará pela unidade substancial. Por fim, se a alegoria e a tipologia permitiam decifrar e posicionar os diferentes significantes (personagens e eventos), segundo a hierarquização da multiplicidade dos significados, a concórdia agora possibilitará dar um passo decisivo na direção da unidade.

Com a concórdia, Joaquim pretende, portanto, apreender a unidade na diversidade dos significados. Também pretende obter uma síntese ou redução do significado que, para dizer de algum modo, póe em suspensão as dimensóes temporais e espaciais da matéria histórica, isto é, dos diferentes tipos e eventos distribuídos e posicionados pela tipologia, ao longo dos três estados do mundo. E, além disso, pretende elevar ao máximo a compreensão espiritual (spiritualis intellectus) da escritura e da própria história em curso, à medida que reduz os diferentes significados a um só. 
É isso que decorre, em suma, dessa proposta que visa a reduzir a multiplicidade dos significantes a um só significado. Eis a regra básica desse método: cada dois (ou três) significantes manifestam um único significado (duo igitur significantia sunt unum significatum) (JOAQUIM DE FIORE, 1964a, f. 7 b-c).

Na concórdia, não há, com efeito, uma relação horizontal entre o anúncio e a realização dos dois testamentos, como na tipologia; tampouco há uma relação vertical entre a letra e o espírito no interior dos dois testamentos, como na alegoria. A proposta agora é a de verificar a repetição de um mesmo significante, sob a forma de outro significante equivalente; e ambos os significantes náo estarão mais hierarquizados, mas serão exatamente substituíveis um pelo outro. Tomemos um exemplo. Em uma passagem da Concordia, Joaquim (1964a, f. 31c) assinala que Abraão (Antigo Testamento) "[...] significa o mesmo" (idipsum significat) que Zacarias (Novo Testamento); Isaac (AT) significa o mesmo que João Batista (NT); e Jacó (AT), o mesmo que Jesus (NT).

Em outra passagem emblemática do mesmo texto, Joaquim (1964a, f. 7 b-c) define o método por concórdia e exemplifica o seu funcionamento, nos termos seguintes:

Por concórdia, entendemos mais propriamente a similitude entre iguais proporçóes que se estabelecem entre o Novo e o Antigo Testamento. E digo iguais quanto ao número, não quanto à dignidade. Assim, um personagem corresponde a outro personagem, uma ordem à outra ordem e uma guerra a outra guerra; e esta paridade é tal como se um (personagem) olhasse na face do outro. Assim, por exemplo, são correspondentes Abraão e Zacarias, Sara e Isabel, Isaac e João Batista, o homem Jesus e Jacó, os doze Patriarcas e o mesmo número de Apóstolos, e outros tantos similares. E tudo o que ocorre nestes casos não é alcançado mediante o sentido alegórico, senão pela concórdia entre os dois testamentos, pois de ambos resulta uma única compreensão espiritual.

Os exemplos trazidos por Joaquim mostram bem a distinção entre o método alegórico, o tipológico e o por concórdia. Em relação à prática alegórica, fica claro que a concórdia não implica a passagem de um significante literal ou histórico para um espiritual, mediante a atribuição de cinco significados correspondentes. Se assim fosse, a interpretaçáo alegórica dos tipos citados acima - a saber: Abraão e Zacarias, Sara e Isabel, Isaac e João Batista, Jesus e Jacó, os doze Patriarcas e os doze Apóstolos -, teria de seguir 
os significados resultantes do esquema das cinco relaçóes divinas, atribuindo cinco significados diferentes a cada um dos personagens.

O mesmo ocorre com a interpretação tipológica. A relação por concórdia não remete, como na tipologia, a uma hierarquização dos tipos de acordo com o esquema de anúncio e realização em três estados consecutivos. Tampouco os mesmos tipos seráo caracterizados mediante os sete sentidos tipológicos, resultantes do esquema trinitário assegurados pelos modos de dizer a trindade de Deus qua Deus.

A concórdia, em suma, ao igualar os significantes de acordo com uma correspondência numérica, reduz os significados; e, com isso, permite a plena equiparação entre os tipos relacionados. Em última instância, um tipo singular ou coletivo será perfeitamente identificado com outro; e, desse modo, um tipo situado em um estado do mundo passará a ser o mesmo que outro tipo localizado no mesmo lugar em outro estado.

\section{Condenaçóes E ATUalidade}

A teoria trinitária de Joaquim de Fiore foi alvo de uma primeira condenação no IV Concílio Lateranense de 1215 (DENZINGER; SCHONMETZER, 1967), dez anos após a morte do abade. Mais tarde, voltou a ser alvo da censura da comissão eclesiástica, reunida em Anagni, entre 1255-56 (VERARDI, 1992; ROSSATTO et al., 2010), que, ao condenar o opúsculo Introductorio in Evangelium eternum, do jovem franciscano Geraldo de Borgo, tentará estender a mesma condenação à totalidade dos textos de Joaquim, que estavam na raiz dessa polêmica obra. Uma última tentativa de condenação, sem sucesso, será levada a cabo no Concílio de Arles, em 1263.

O principal problema apontado na teoria trinitária joaquimita, segundo relatam as atas do Concílio Lateranense, confirmadas pelo Protocolo de 1255 , é a afirmação da unidade trinitária por coletividade. Na verdade, a primeira condenação teve como base apenas o opúsculo Sobre a unidade ou essência da Trindade, em que o monachus acusava o magister Pedro Lombardo de professar a heresia quaternarista. Ao lado das disputas sobre a autoria desse texto condenado, ainda hoje desaparecido, certo é que a mesma crítica dirigida contra Lombardo e a própria formulação da unidade trinitária por coletividade se encontram em outros dois textos autênticos do abade, o Psalterium decem chrodarum (1964b, f. 229ss) e o De vita sancti Benedicti (1953, p. 56ss). 
Certo é que o abade acusou duramente o magister Pedro Lombardo, tachando-o de herético e louco, por haver afirmado a unidade trinitária como uma "suma coisa" (summa res), o que, a seu juízo, incidiria no quaternarismo. Em contrapartida, Joaquim será condenado por triteísmo pelos documentos eclesiásticos, sob a alegação de ter afirmado a unidade trinitária por coletividade. Também é certo que o abade sugere a enunciação da unidade trinitária em analogia com termos coletivos, tais como tribus, plebs e populus, entre outros. E, na medida em que os documentos eclesiásticos sustentam que tais termos são inapropriados para indicar corretamente a unidade divina, a conclusão não poderá ser outra: a teoria trinitária joaquimita professa três pessoas separadas entre si, configurando um caso de triteísmo.

Não vamos entrar aqui no mérito dessas disputas que, além de focalizarem o problema técnico atinente ao emprego de termos apropriados para referir a unidade da Trindade, póem em confronto duas mentalidades em conflito na época: a mentalidade monástica, na qual o abade Joaquim fora formado, e a nova mentalidade escolástica, que se afirmava por aqueles dias. Dessa perspectiva, poderíamos contra-argumentar a favor de Joaquim, enfatizando que, em seu modelo trinitário, diferentemente da terminologia escolástica, os vocábulos coletivos são indicadores de realidades substanciais comuns, anteriores e superiores às propriedades individuais dos singulares isolados. E, devido a isso, tais termos seriam consistentes para sugerir de forma análoga a unidade da substância divina. Da mesma maneira, poderíamos contra-argumentar que o abade se mantinha fiel à terminologia trinitária clássica, utilizada longamente pela tradição Patrística, sobretudo pelo De Trinitate de Agostinho, por ele tantas vezes citado. Em suma, para Joaquim, os termos coletivos, a exemplo das coletividades monásticas - a comunitas não estariam nomeando, como no realismo escolástico, entidades separadas entre si. Tampouco as espécies inteligíveis (species intelligibilis) são abstraídas dos entes singulares naturais, como quer a escolástica.

Não obstante, um dos pontos relevantes para nosso estudo é mostrar que o fantasma do triteísmo acompanhará, de diferentes modos - e na maioria das vezes de forma não declarada -, a recepção das ideias de Joaquim de Fiore, provocando algumas distorçôes localizadas em sua hermenêutica e na teoria da história, todas elas radicadas na má compreensão da noção de Trindade.

A questão que nos guia doravante é a seguinte: que problemas resultam da má compreensão do modelo trinitário joaquimita, em termos da recepção de sua teoria hermenêutica e da leitura da história. Veremos isso, resumidamente, 
em três momentos específicos da recepção subsequente das ideias do abade de Fiore.

1. Um dos momentos problemáticos da recepção do pensamento de Joaquim é aquele documentado pelo Protocolo de Anagni, de 1255, por ocasião da condenação do Introdutorio in Evangelium Eternum, de Geraldo de Borgo. As atas da Comissão de Anagni têm seu foco centrado no que toca à aplicação dos pressupostos da teoria trinitária aos acontecimentos e tipos que viriam a ocorrer na passagem do segundo para o terceiro estado; mais precisamente, do ano 1260 até o final do século XIII.

Como bem observa Marjorie Reeves (1980, p. 40), se o pensamento mais original de Joaquim está condensado em sua noção de Trindade, a qual se manifesta plenamente em todos os eventos realizados no tempo, sem dúvida o maior impacto se produz com o prognóstico da realização do terceiro estado, no qual culminaria todo o processo da sucessiva iluminação divina, no próprio curso da história humana. Por isso, um dos aspectos mais problemáticos do pensamento joaquimita reside justamente na compreensão desse momento de transição do segundo para o terceiro estado do mundo, que marcaria a consumação (consumatio) do período protagonizado pelo Filho, em que o cristianismo daria lugar a um mais elevado estado espiritual. $\mathrm{O}$ outro aspecto, náo separado deste, diz respeito ao Evangelho eterno: o testamento da terceira pessoa da trindade, que entraria em vigor no terceiro estado do mundo.

De acordo com os precisos cálculos resultantes da hermenêutica joaquimita, Geraldo de Borgo entende que o terceiro estado da história se iniciava por aqueles dias, mais precisamente nas geraçóes próximas ao ano 1260 . Com isso, teríamos a consumação do estado do Filho e, consequentemente, de seu evangelho (o Novo Testamento) e de sua ordem de eleitos, a ordem clerical (ordo clericorum). Em troca, logo surgiria uma Igreja Espiritual renovada, guiada por um terceiro testamento - o Evangelho do Espírito ou Evangelho Eterno -, e encabeçada por nova ordem monástica (ordo monachorum).

Até aqui, Geraldo não introduz nada de novo na hermenêutica joaquimita. A novidade aparece exatamente quando ele atualiza alguns dos prognósticos deixados por esse modelo interpretativo. Em uma das passagens da Concórdia, Joaquim (1964a f. 60ss) apontava para o surgimento de três grandes tipos, no decorrer de cada um dos três estados do mundo. Partia da constatação de que, no início do primeiro estado, surgiram Abraão, Isaac e Jacó; e, de igual modo, no do segundo, aparecem Zacarias, João Batista e Jesus. 
Com base nisso, Joaquim, mediante o procedimento por concórdia, assegurava que três personagens idênticos, porém mais elevados em dignidade, viriam no início do terceiro estado do mundo. $\mathrm{O}$ primeiro deles estava indicado no versículo em que o profeta Daniel (Dn 12,7) afirmava ver um homem vestido de linho andar por cima das águas. Os outros dois estavam prognosticados no Apocalipse de João: o anjo que traria o Evangelho Eterno, proclamando-o como o "selo do Deus vivo» (Ap 7, 2); e o outro anjo que viria, com a foice afiada, como um "filho do homem" (Ap 14,14).

Geraldo, por sua vez, dará um passo mais nessa hermenêutica, ao aplicá-la a três personagens de sua época. O jovem franciscano, assim, passa a entender que o homem vestido de linho era o próprio Joaquim de Fiore (1130-1202); o anjo com a foice afiada era Domingos de Gusmão (11701221), o fundador da ordem dominicana; e o anjo com o «selo do Deus vivo», portador do Evangelho do Espírito, previsto por Joaquim para surgir nas geraçóes próximas a 1200, era nada menos que Francisco de Assis (11821226), o fundador de sua ordem, a franciscana. Por conseguinte, a ordem franciscana seria a nova ordem monástica, destinada a protagonizar o terceiro e último estado do mundo.

A nosso ver, um dos aspectos problemáticos dessa hermenêutica é o exagerado destaque dado à tríade pessoal da Trindade, associada aqui às três figuras prognosticadas para o início de cada estado, em detrimento da unidade substancial, que perfilaria a íntima ligação entre elas. Além da ausência da unidade substancial, a articulação entre as pessoas, aqui caracterizada por cada um dos estados, é feita por oposição exclusiva e, consequentemente, tudo aquilo que é próprio às figuras em cada estado se opóe. Seria o mesmo que afirmar que há uma luta entre as pessoas divinas no interior da Trindade e esta é deslocada para dentro da história humana. Tal hermenêutica, a rigor, impede a perfeita transposição ao plano da história da imagem da Trindade proposta pelo abade, como três são um e um três. Temos, ao final, uma das variantes do triteísmo trinitário, que se duplica aqui como um triteísmo histórico. $\mathrm{O}$ triteísmo histórico náo se caracteriza apenas por sublinhar em demasia os atributos pertinentes a cada uma das pessoas da tríade - e, neste caso, isolar a figura do Espírito, em detrimento das outras duas -, mas também por provocar o tácito esvaziamento da unidade substancial.

Em Geraldo de Borgo, esse problema se torna mais visível na relação exclusiva entre os tipos próprios ao segundo e terceiro estados do mundo. Ele, assim, pensa que as figuras próprias ao segundo estado - como, por exemplo, 
o papado romano (Pedro) e o clero secular (ordem dos clérigos) - seriam eliminadas (e não consumadas) no momento da transição para o terceiro, ou seja, na luta contra o primeiro Anticristo, quase sempre associado à figura política negativa do Imperador dos últimos dias. Em seu lugar, floresceria soberanamente um Papa angélico (João), como Novo guia (Novus dux), e uma nova ordem monástica (a franciscana). Também as mediaçóes próprias ao segundo estado, entre elas os sacramentos (batismo, matrimônio etc.) e o Evangelho de Cristo (Novo Testamento), perderiam sua função, dando lugar ao que seria próprio ao novo estágio da história: o Evangelho Eterno, como um Verbo eterno sine littera.

É digno de nota que alguns dos traços básicos dessa tipologia do terceiro estado joaquimita reaparecerão em diferentes manifestaçóes populares da cultura luso-brasileira (cf. ROSSATTO, 2003 e 2005) e em episódios da história recente, como também na ficção literária. As festividades do Império do Divino Espírito Santo, originadas em Portugal durante o período medieval, são um dos exemplos mais visíveis da sobrevivência da hermenêutica joaquimita na cultura luso-brasileira. Ainda hoje se conservam quase intactos os vestígios do esquema trinitário nas figuras dos três reis, em que ao centro, como protagonista, como Novo guia (Novus $d u x$ ) da era do Espírito se destaca um rei menino. Para Joaquim (1964a, f. 56b e f. 12a), o terceiro estado seria comandado pelas crianças, em contraste com o primeiro e o segundo, encabeçados respectivamente pelos velhos e os homens jovens e maduros. No substrato cultural brasileiro, é comum também o reaparecimento da figura do monge, tanto em eventos históricos quanto na ficção literária. Na hermenêutica de corte joaquimita, o monge não pertence à ordem dos casados nem à dos clérigos, pois não existe mais a necessidade da mediação dos sacramentos. $\mathrm{Na}$ nossa história recente, podemos destacar os três monges da Guerra do Contestado (1912-16), o movimento dos Monges do pinheirinho (1902, Encantado, RS) e dos Monges barbudos (1935-38, Soledade, RS), no sul do país; e ainda, no nordeste brasileiro, a conhecida figura de Antônio Conselheiro, na Guerra de Canudos (1896-97), entre outros. Na ficção literária, um dos exemplos mais contundentes é o romance A Pedra do Reino (1971), de Ariano Suassuna.

2. Outro momento da recepção problemática do pensamento joaquimita é aquele que associa as ideias do abade às modernas filosofias da história. Essa tendência reencontra facilmente a perspectiva espiritual e a estrutura da teoria da história do abade na noção de espírito livre (freien Geist) do idealismo alemão (sobretudo em Lessing, Schelling, Fichte e Hegel), 
nos trois états do positivismo de Augusto Compte e nas diferentes tríades da dialética hegeliano-marxista. Entre os representantes dessa tendência historiográfica podemos citar: Norman Cohn (1957), Karl Löwith (1961), Henry Mottu (1977 e 1980) e Henri De Lubac (1979 e 1981). Em geral, esses estudiosos se centram em um esquema triádico aplicado à história; e, na sequência, encontram o último e mais elevado estágio da história em um cristianismo renovado (ou reformado) ou na sola figura do espírito. Dessa perspectiva, reaparece, entáo, a ideia joaquimita de terceiro estado do espírito na base das modernas heresias, das reformas protestantes, dos movimentos anarquistas e das noções de progresso histórico e de revolução.

Não vamos nos deter nos detalhes dessa rica, complexa e demasiado ampla tentativa de aproximaçáo entre Joaquim e os modernos. Tomaremos, de forma muito pontual, apenas o caso de Hegel.

Em seu artigo Joachim de Fiore et Hegel, publicado nas Atti del I Congresso Internazionale di Studi Gioachimiti, Henry Mottu (1980) avalia algumas das tentativas de aproximação entre Joaquim e Hegel. Entre suas ponderaçôes, duas delas nos parecem importantes, no atual estado da questão. A primeira é a de que encontrar a gênese da filosofia hegeliana da história em Joaquim hoje parece "[...] senão ilusório, pelo menos altamente discutível" (MOTTU, 1980, p. 159). Em troca, Mottu (1980, p. 159) admite - e aí temos a segunda ponderação -, que "incontestavelmente" podemos encontrar "[...] alguns traços da herança joaquimita” em Hegel. Entre esses traços, ele aponta o esquema trinitário aplicado à história e a noção de progresso histórico. Avaliaremos apenas esses dois aspectos.

Para mostrar que a filosofia da história de Hegel não segue tão somente um esquema ternário, mas trinitário, Mottu seleciona algumas passagens da Fenomenologia do espirito (capítulo VII), das Liçóes sobre a filosofia da religiáo e, principalmente, das Liçôes sobre a filosofia da história universal. Com base nessas passagens, ele inicialmente argumenta que Hegel, tal como Joaquim, periodiza o devir do mundo como o movimento do Espírito, que se realiza enquanto liberdade crescente ao longo de um processo histórico tripartido. E mais: que esse esquema tripartido, que se expressa pelos termos Pai, Filho e Espírito Santo, póe em evidência a figura do Espírito como perspectiva de realização do progresso histórico.

Mottu (1980, p. 163) dá especial destaque a uma passagem das Liçóes sobre a filosofia da história universal de Hegel (1997, p. 660), que associa o 
«reino do Filho» à Idade Média e o "reino do Espírito» à Reforma. Nessa oportunidade, Hegel escreve claramente que Deus, ao se exteriorizar no mundo como Filho, não encontra sua plenitude, pois ela só viria com a figura do Espírito, depois que o Filho fosse "revogado" (aufgehoben). E acrescenta, na sequência, que a "última bandeira" é a do espírito livre (des freien Geistes), com sua "nova Igreja" e seu "reino da liberdade espiritual".

Não obstante, para mostrar a ideia de progresso no interior do sistema hegeliano, Mottu se baseia em outra passagem das Liçôes (HEGEL, 1997, p. 132), que considera o desenvolvimento do espírito a partir de três épocas: a primeira é o espírito infantil, associado ao mundo oriental; a segunda é o espírito jovem e maduro, relacionado ao mundo greco-romano; e a terceira é a época da senilidade do espírito, com o mundo cristão.

Com base nesta passagem, Mottu (1980, p. 166) conclui que, apesar da utilização do esquema trinitário por ambos os autores, a evolução interna ao esquema é invertida. Ele sublinha que, no filósofo alemão, o progresso do espírito segue uma evolução biológica, caracterizada pela passagem da infância para a maturidade e a velhice; Joaquim, por sua vez, como já destacamos, segue um caminho contrário ao da evolução natural: vai da velhice para a infância, passando pela juventude e maturidade. Assim, apesar das semelhanças, esse importante traço, que possibilitaria comprovar uma maior aproximaçáo entre os dois autores, não se confirma em seus detalhes.

Porém, a nosso ver, a argumentação não se sustenta plenamente, quando for confrontada com outra passagem das mesmas Liçóes (HEGEL, 1995, p. 573), a qual apresenta mais visivelmente o esquema trinitário, ao fazer a periodização do mundo germânico:

Podemos distinguir estes períodos como os reinos do Pai, do Filho e do Espírito. O do Pai é a massa substancial e indivisa, em mera transição, como o reinado de Saturno, que devora seus filhos. O reino do Filho é o aparecimento de Deus, porém apenas em relaçáo à existência temporal, surgindo como algo estranho. $\mathrm{O}$ reino do Espírito é a reconciliação.

A julgar por essa passagem, não haveria propriamente uma inversão do esquema joaquimita da história em relação ao hegeliano, como sugere Mottu, pois, nesse caso, o "reino do Pai", associado à velhice - o terribilis dominus do Antigo Testamento, para Joaquim, o domínio do velho Saturno, para Hegel -, marca para os dois autores o primeiro e mais rudimentar estágio 
da humanidade. Por certo, os outros dois estágios, mais avançados, estariam associados respectivamente à maturidade e à infância. Nesse caso, para Hegel, a perspectiva de aperfeiçoamento do espírito seguiria um sentido que vai da velhice para a infância, passando pela juventude e maturidade, e não o contrário. Assim, esse traço, que possivelmente aproximaria Joaquim e Hegel, seria bem mais visível do que propóe o estudo de Mottu.

Se nossa argumentação for procedente, como, então, explicar a incongruência entre os próprios esquemas hegelianos?

Ao que parece, não haveria propriamente uma incongruência. No caso em que se sobressai o esquema biológico, Hegel estaria se reportando tão somente ao que é próprio à obra do espírito, no interior de cada uma das figuras trinitárias, com base na relação entre o indivíduo e o universal. Ele, dessa forma, compara o progresso do espírito, no interior de cada pessoa da Trindade, com a evolução natural do indivíduo humano. Cabe notar, na passagem hegeliana em que Mottu se apoia, para afirmar o movimento biológico, que o acento está colocado na figura do espírito, enquanto progresso da ideia de liberdade individual, e não na paterna ou filial. A primeira fase é a da infância do espírito, no mundo oriental, onde ele opera segundo o Pai e, por isso, prevalece o patriarcalismo em que a vontade de um indivíduo se impóe à dos demais. A segunda fase é a da juventude e maturidade do espírito, no mundo greco-romano, em que ele opera segundo o Filho e, então, deixa de prevalecer a obediência de escravo e passa a vigorar um tempo de maior liberdade filial. A terceira fase é a da senilidade do espírito, com o mundo cristão, em que ele opera segundo o próprio Espírito e alcança a plenitude da liberdade individual.

Assim, o movimento do espírito, no interior de cada uma das três figuras trinitárias, seria natural, cíclico ou biológico. E, nesse caso, ao invés de uma diferença entre Joaquim e Hegel, verificaríamos um traço mais na aproximação entre os autores. Para Joaquim, o movimento interno a cada um dos estados do mundo, representado pela emblemática figura dos três círculos entrelaçados, segue um curso cíclico, biológico ou natural em três fases, a saber: a germinação, a frutificação e a consumação de cada um dos três estados. Outro, porém, seria o movimento realizado pelo deslocamento das três figuras trinitárias, ao longo dos três estados do mundo. O deslocamento do Filho em relação ao Pai e o do Espírito em relação aos dois, que caracteriza a evolução do espírito na história geral, e não a operação de uma figura da Trindade no interior da outra, se dá numa ordem inversa à biológica. 
Neste segundo caso, também não se verifica um movimento cíclico, que tem como modelo a natureza, mas um movimento horizontal de perspectiva teleológica, o qual realiza um traçado inverso ao deslocamento natural ou cosmológico. É esta, aliás, a diferença entre a natureza e a história, para Hegel. A lógica natural é implacável: das cinzas da fênix mítica sairá outra ave sempre igual; das cinzas da história, ao contrário, erguer-se-á uma nova e mais elevada figura do espírito. Mas, nesse momento, já não estaríamos mais falando tão somente do espírito como terceiro termo da tríade, mas como substância que anima e lança para frente a totalidade da história.

Com essas observaçóes, não pretendemos pôr um ponto final na discussão. Ao contrário, queremos reabri-la a partir da exposição de alguns aspectos contraditórios que, de outro modo, remetem à complexidade alcançada pelos esquemas triádicos, em ambos os autores. Com certeza, colocamos em questão a própria tentativa de fazer uma simples homologia de estruturas, pois, no fim das contas, acaba-se por desfigurar a ambos os autores e sistemas. Nesse mesmo sentido, cabe observar que a noção medieval e joaquimita de providência atuando no mundo e a ideia moderna e hegeliana de progresso da história guardam semelhanças, com certeza, mas também abrigam diferenças significativas.

3. Por fim, passamos à análise bastante sumária da proposta de Gianni Vattimo (2004). Em Dopo la cristianità, escrito em 2002, o autor italiano procura retomar os "ensinamentos de Joaquim" como alternativa à discussão atual dos temas da secularizaçáo e da morte e retorno de Deus.

Com o objetivo de recolocar a discussão do decreto da morte de Deus no próprio curso evolutivo da história do cristianismo, Vattimo sustenta sua posiçáo em sintonia com a perspectiva inaugurada pela hermenêutica de Joaquim de Fiore. Com base nessa perspectiva, ele pretende se distanciar de algumas das posiçốes atuais que, seja pela influência de Emmanuel Lévinas, seja de Jacques Derrida, concebem a Deus como uma "abertura ao totalmente Outro"; o que, a seu juízo, não passaria de um retrocesso à "teologia da primeira idade" joaquimita, ao "Deus do Antigo Testamento" judaico, ao "velho Deus da metafísica" dos filósofos ou ao primitivo "Deus 'violento' das religiôes naturais" (VATTIMO, 2004, p. 52-54). Contra a avaliação do processo de secularizaçáo que almeja retornar ao modelo dos antigos deuses, distantes, opressores e violentos, que, com certeza, trazem as marcas características ao Deus-Pai do primeiro estado do mundo joaquimita, Vattimo propóe a volta 
ao Deus-Filho do segundo estado e também (o que para nós não é tão claro) ao Deus-Espírito do terceiro.

Náo vamos nos deter no mérito da leitura crítica que o pensador italiano faz do processo de secularização; tampouco ao que ele considera um "salto" ou "reviravolta" em direção ao Deus antigo, arcaico, totalmente Outro. Vamos nos centrar apenas em sua intenção de retomar a secularização, como ideia de "[...] cumprimento de uma história da salvação que foi guiada, desde o início, pelo fio condutor da morte de Deus - isto é, da dissolução do sacro, da liquidação da transcendência..." (VATTIMO, 2004, p. 53), à luz dos ensinamentos de Joaquim. É nesse sentido preciso que faremos uma observação pontual.

Se bem entendemos, o pensador italiano, no fim das contas, propóe a retomada de um novo cristianismo encarnado como alternativa e contraponto ao Deus metafísico dos filósofos, arcaico das religióes naturais e bíblico do Antigo Testamento. Não obstante, é preciso ter presente que, no esquema joaquimita dos três estados, o cristianismo, como estado do Filho, teria seu cumprimento nas últimas geraçôes do século XIII, dando lugar a um novo e mais elevado terceiro estado espiritual. Dessa forma, parece-nos que, se o filósofo italiano pretende ser fiel ao pensamento do abade calabrês, em um sentido deveria sugerir a própria superação do cristianismo; e, em outro, propor em seu lugar a renovada era espiritual joaquimita. Ao contrário, sua proposta, como sugere o próprio título do livro Depois da cristandade, aponta mais para a substituição do que ele concebe por "cristandade" pelo que ele passa a entender por "cristianismo". Nesse aspecto, a tradução brasileira acrescenta um subtítulo que qualifica esse novo cristianismo proposto por Vattimo como "um cristianismo não religioso".

De qualquer modo que tomarmos o termo "cristianismo" - ou mesmo a expressão "cristianismo não religioso" ou cristianismo secularizado -, não vamos aí encontrar as características próprias ao estado espiritual joaquimita. Também, ao final, não reencontraremos o esquema joaquimita dos três estados, em que o terceiro estado espiritual entraria em vigor logo após o cumprimento do segundo estado filial, isto é, o do cristianismo, e não depois de mais de dois mil anos de uma difusa "cristianità", que não se sabe efetivamente o que é. E assim, em última análise, a retomada de Joaquim por Vattimo curiosamente acabaria apenas reeditando o que encontramos nas antigas teorias trinitárias anteriores ao abade, que sempre acabam suprimindo ou mesmo subsumindo a figura do Espírito, em benefício da velha ordem patriarcal ou da renovada ordem filial. 
ROSSATTO, Noeli Dutra. Medieval Hermeneutics: the spiritual comprehension of Joachim of Fiore. Trans/Form/Ação, Marília, v. 35, p. 99-118, 2012. Edição Especial.

\begin{abstract}
The study deals with medieval hermeneutics from the viewpoint of spiritual comprehension (intelectio spiritualis) in Joachim of Fiore (1135-1202). The theologian shows that the notion of the Trinity serves as a basis for the rebuilding of the traditional allegorical and typological methods. Moreover, he proposes a new method by harmony which, in our view, culminates in an innovative reading of history. We highlight the immediate continuity of said hermeneutics with the Franciscans of the XIII century, and their direct influence on Luso-Brazilian culture. We also evaluate studies that attempt to find in Joachim the genesis for the Hegelian philosophy of history. Finally, we analyze Gianni Vattimo's proposal, which finds a new meaning for Christianity in the Joachimite legacy.
\end{abstract}

KEYWORDS: Hermeneutics. Joachim of Fiore. Exegesis. Allegory. Typology.

\title{
REFERÊNCIAS
}

BUONAIUTI, E. Gioacchino da Fiore. I tempi, la vita, il messagio. Roma: Meridionale, 1931.

CANTIN, A. Fede e dialettica nell'XI secolo. Milano: Jaca Book, 1996.

COHN, N. The Pursuit of the Millennium. Revolutionary, Millenarians and Mystical Anarchists in the Middle Ages. London: Paladin, 1957.

DE LUBAC, H. La postérité spirituelle de Joachim de Flore. Tomo I - de Joachim à Schelling. Paris: Lethielleux, 1979.

. La postérité spirituelle de Joachim de Flore. Tomo II - de Saint Simon à nous jours. Paris: Lethielleux, 1981.

. Exégèse médiévale. Les quatre sens de l'écriture. Seconde parte. Paris: Aubier, 1961.

GRUNDMANN, H. Studien über Joachim von Fiore. Stuttgard: Teubner, 1966.

HEGEL, G. W. F. Lecciones sobre la filosofía de la historia universal. Madrid: Alianza, 1997.

JOAQUIM DE FIORE. Concordia Novi ac Veteris Testamenti. Venedig, 1519, reedição facsímile Frankfurt: Minerva, 1964a.

. Psalterium decem chordarum. Venedig, 1527, reedição fac-símile Frankfurt: Minerva, $1964 \mathrm{~b}$.

- De vita sancti Benedicti et de officio divino secundum eius doctrinam. Editado por Cipriano Baraut. Analecta sacra Tarraconensia, Barcelona, v. 24, p. 42-118, 1953. 
LÖWITH, K. Weltgeschichte und Heilsgeschehen. Die theologischen voraussetzungen der Geschichtsphilosophie. Stuttgart:Kohlhaummer, 1961 (Anexo I: Verwandlungen der Lehre Joachims, p. 190-95).

MAFFESOLI, M. A contemplação do mundo. Porto Alegre: Artes e Ofícios, 1995.

MOTTU, H. La manifestation de l'Esprit selon Joachim de Fiore. Neuchâtel-Paris: Delachaux \& Niestlé, 1977.

. Joachim de Fiore et Hegel. In: CONGRESSO INTERNAZIONALE DI STUDI GIOACHIMITI, I, 1980, San Giovanni in Fiore. Atti... Centro di Studi Gioachimiti, 1980, p. 153-175.

REEVES, M. How original was Joachim of Fiore's Theology of History? In: CONGRESSO INTERNAZIONALI DI STUDI GIOACHIMITI, I, 1980, San Giovanni in Fiore. Atti... Centro di Studi Gioacchimiti, 1980, p. 27-41.

ROSSATTO, N. D. Joaquim de Fiore: Trindade e Nova Era. Porto Alegre: EDIPUCRS, 2004.

. (Org.). O simbolismo das Festas do Divino Espirito Santo. Santa Maria: FacosUFSM/FAPERGS, 2003.

. L'Abate Gioacchino e la Festa del Divino: una celebrazione luso-brasiliana dell'Età dello Spirito. Florensia, v. 18-19, p. 173-185, 2005.

- La hermenéutica medieval. Un estudio desde Joaquín de Fiore. Saarbrucken: Lap Lambert-Editorial Académico Española, 2011.

ROSSATTO, N. D. et al. Evangelho eterno: a hermenêutica condenada. Filosofia Unisinos, vol. 11 (3), p. 298-339, 2010.

VATTIMO, G. Depois da cristandade. Por um cristianismo não religioso. Trad. Cynthia Marques. Rio de Janeiro-São Paulo: Record, 2004.

VERARDI, L. Gioacchino da Fiore - Il Protocollo di Anagni. Tradução e reedição do texto latino de H. Denifle: Protocol der Commission zu Anagni - Anno 1255. Cosenza: Orizzonti Meridionali, 1992.

VERGER, J. Il rinascimento del XII secolo. Milano: Jaca Book, 1997.

YOUNG, F. Biblical exegesis and the formation of Christian culture. Cambridge: Cambridge University Press, 1977. 